\title{
UNUSUAL COMBINATION OF REVERSIBLE SPLENIAL LESION AND MENINGITIS-RETENTION SYNDROME IN ASEPTIC MENINGOMYELITIS
}

doi: 10.1590/S1807-59322009000900017

Nida Tascilar, ${ }^{\mathrm{I}}$ Hande Aydemir, ${ }^{\mathrm{II}}$ Ufuk Emre, ${ }^{\mathrm{I}}$ Aysun Unal, ${ }^{\mathrm{I}} \mathrm{H}$. Tugrul Atasoy, ${ }^{\mathrm{III}}$ Sureyya Ekem ${ }^{\mathrm{I}}$

\section{INTRODUCTION}

A circumscribed lesion in the splenium of the corpus callosum (SCC) is a rare finding, and little is known about its etiology. ${ }^{1}$ Reversible splenial lesions in the $\mathrm{CC}$ are observed in various diseases (Table 1). ${ }^{1-33}$

The combination of aseptic meningitis or meningomyelitis and acute urinary retention has been recently acknowledged and, in the absence of accompanying abnormalities, has been referred to as meningitis-retention syndrome (MRS) by some Japanese authors. ${ }^{34,35}$ Only a few reports of MRS are available to date. ${ }^{34-38}$ Although the term meningitis was used, some of the reported cases could in fact have been myelitis in view of the presence of fecal incontinence and brisk reflexes. ${ }^{34}$

To the best of our knowledge, the combination of neurogenic bladder and reversible splenial lesion due to meningomyelitis or to any other condition has not been reported previously. Here, we report a case of an isolated reversible splenial lesion and a neurogenic bladder in a woman with aseptic meningomyelitis.

\section{CASE HISTORY}

A 26-year-old female was admitted to a local hospital with symptoms of acute fever, headache, phonophobia, photophobia, nausea, vomiting, dizziness, appetite loss, and fatigue. She was administered oral cefuroxime axetil

\footnotetext{
${ }^{\mathrm{I}}$ Department of Neurology, Zonguldak Karaelmas University Medical Faculty - Zonguldak, Turkey.

II Department of Infectious Diseases and Clinical Microbiology, Zonguldak Karaelmas University Medical Faculty, Zonguldak, Turkey

III Zonguldak “A” Tip Merkezi (Private Medical Clinic), Zonguldak, Turkey Email: doga24@yahoo.com

Tel: 903722667375
}

Table 1 - Etiologies of isolated reversible lesions in the splenium of the corpus callosum

\begin{tabular}{|c|c|c|}
\hline Etiology & $\begin{array}{c}\text { \# of } \\
\text { pts }\end{array}$ & $\begin{array}{l}\text { Pathophysiology } \\
\text { (vasogenic/cytotoxic edema) }\end{array}$ \\
\hline $\begin{array}{l}\text { Encephalitis/Encephalopathy/ } \\
\text { Cerebellitis }^{2-12}\end{array}$ & 30 & $\begin{array}{l}\text { Intramyelinic, cytotoxic edema, } \\
\text { inflammatory infiltrate }\end{array}$ \\
\hline $\begin{array}{l}\text { Antiepileptic drug usage or } \\
\text { withdrawal }^{13-18}\end{array}$ & 24 & vasogenic/cytotoxic edema \\
\hline Epilepsy ${ }^{1,12,19-21}$ & 20 & vasogenic edema \\
\hline High-altitude illness $^{22}$ & 7 & vasogenic edema \\
\hline $\begin{array}{l}\text { Systemic lupus erythemato- } \\
\text { sus }^{23.24}\end{array}$ & 4 & $\mathrm{~nm}$ \\
\hline Methyl bromide poisoning ${ }^{25}$ & 2 & $\mathrm{~nm}$ \\
\hline Malnutrition ${ }^{26,27}$ & 2 & probable vasogenic edema \\
\hline $\begin{array}{l}\text { Hypoperfusion due to meta- } \\
\text { bolic changes }^{28,29}\end{array}$ & 1 & probable focal cytotoxic edema \\
\hline $\begin{array}{l}\text { Hemolytic-uremic syn- } \\
\text { drome }^{30}\end{array}$ & 1 & vasogenic edema \\
\hline Charcot-Marie-Tooth ${ }^{31}$ & 1 & $\mathrm{~nm}$ \\
\hline Aseptic meningitis ${ }^{32}$ & 1 & cytotoxic edema \\
\hline $\begin{array}{l}\text { Aseptic meningomyelitis } \\
\text { (present case) }\end{array}$ & 1 & cytotoxic edema \\
\hline
\end{tabular}

pts: patients; \#: number; nm: not mentioned.

and $0.9 \%$ intravenous saline for two days, with a diagnosis of dehydration and acute sinusitis. She took the antibiotic for two days. She was then evaluated by another clinician due to suspicion of meningitis based on marked neck stiffness and a positive Kernig's sign, and was administered Procaine penicillin for one day and cefazolin for four days. Because of persistent fever, she was referred to our hospital. On admission, her complaints were only headache and fatigue, and she presented a fever of $39.5^{\circ} \mathrm{C}$. Her physical examination revealed no distinct findings or any definite signs of meningeal irritation or mucocutaneous lesions. 
She was alert, fully conscious, and was well oriented. Her sensation, including the perineal area, was normal. She demonstrated no signs of encephalopathy. Her neurological examination showed only right truncal and gait ataxia. She presented no seizure or head trauma, and she was not taking any antiepileptic drugs.

Laboratory examination revealed normal C-reactive protein, with a normal white blood cell count but a high erythrocyte sedimentation rate $(40 \mathrm{~mm} / \mathrm{h})$. The only laboratory test performed before she was accepted to our hospital was urinalysis, which revealed a density of 1030. The blood chemistry, urinalysis, and immunoglobulin concentrations $(\mathrm{G}, \mathrm{A}$, and $\mathrm{M})$ were normal. The cerebrospinal fluid (CSF) examination showed a mononuclear leukocytosis of $408 / \mathrm{mm}^{3}$, increased protein content of $165 \mathrm{mg} / \mathrm{dl}$, and a mildly decreased glucose level of $38 \mathrm{mg} / \mathrm{dl}$ ( $34 \%$ of serum glucose). Bacterial smears and cultures, including tuberculosis, were negative. No increase in oligoclonal bands and a mild increase in the IgG index (0.8) were observed in the CSF. The CSF enzyme immunoassay demonstrated negative IgM antibodies against herpes simplex virus type-1 (HSV-1) and herpes varicella zoster (VZV) viruses. Neither tuberculosis nor HSV was detected in her CSF sample by polymerase chain reaction (PCR). Furthermore, brucella agglutination was negative in the CSF.

Serological tests on the blood samples -- brucella agglutination, salmonella agglutination, brucella Coombs, and VDRL -- were negative. Western blot examination revealed that the samples were negative for $\operatorname{IgM}$ and $\operatorname{IgG}$ antibodies against Borrelia burgdorferi and IgM antibodies against HSV-1. Anti-ds DNA, Ena Jo-1, Ena SCL70, Ena Sm, Ena Sm-RNP, Ena SsA, Ena SsB, anti-cardiolipin, and anti-phospholipid antibodies were also negative. The lipid profile, fibrinogen, homocysteine, antithrombin III, and protein $\mathrm{C}$ and $\mathrm{S}$ levels were all within normal ranges.

Electroencephalography (EEG), echocardiography, and abdominal and urinary ultrasonography were normal. Cranial magnetic resonance images (MRI) on admission demonstrated an isolated small lesion in the SCC that was markedly hyperintense on diffusion-weighted images (DWI), fluid-attenuated inversion recovery (FLAIR) images, and T2-weighted images (T2WI); hypointense on the apparent diffusion coefficient (ADC) and slightly hypointense on T1-weighted images (T1WI) (Figure 1). Some increase was observed only in the enhancement of the leptomeninges (Figure 1A).

Four days later, the patient developed lower abdominal pain and one episode of fecal incontinence. The urinary bladder was distended and palpable above the symphysis pubis. Catheterization of the urinary bladder yielded some

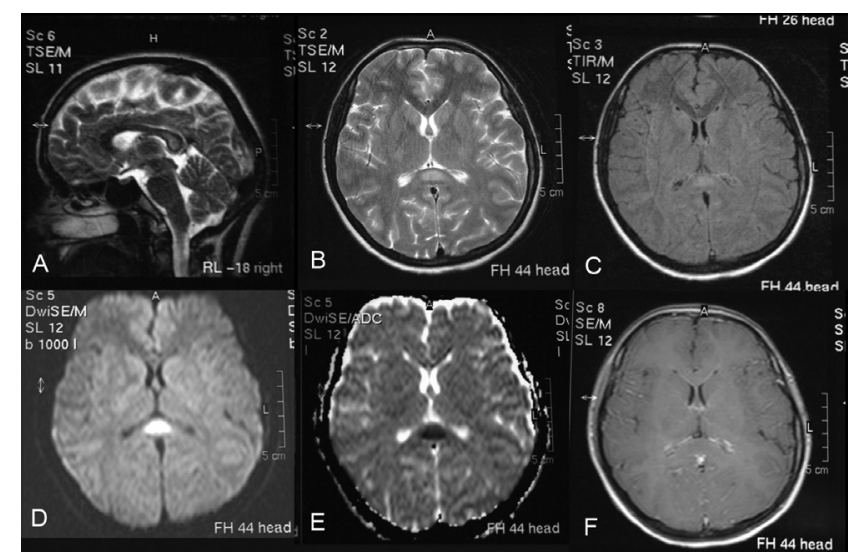

Figure 1 - Sagittal T2-weighted image (a), transverse T2-weighted image (b), transverse FLAIR image (c), and diffusion-weighted image (d) showing a high-intensity signal in the splenium of the corpus callosum. Transverse apparent diffusion coefficient image (e) showing a low-intensity signal in the splenium of the corpus callosum. Contrast transverse T1-weighted image showing only some slight contrast enhancement of the leptomeninges (f)

clear urine. An urodynamic study revealed an acontractile neurogenic bladder, but bladder sensation was spared with a first urge to void after $129 \mathrm{ml}$ of $0,9 \%$ intravesically saline was given. No other neurological abnormalities were detected. Spinal cord MRI revealed that the cervical and thoracic spinal cord was swollen. T2WI showed diffuse high-signal intensity inside the cervical and thoracic spinal cord (Figure 2A). The pia mater over the cervical spinal cord, the thoracic spinal cord, and the parenchyma were enhanced heterogeneously, whereas diffuse meningeal enhancement was present over the conus medullaris (Figure $2 \mathrm{~B}, 2 \mathrm{C})$.

Based on the CSF findings, ceftriaxone and acyclovir treatment were started for an initial diagnosis of aseptic meningitis or poorly treated bacterial meningitis. After five days of treatment, the patient was still febrile. Ampicillin

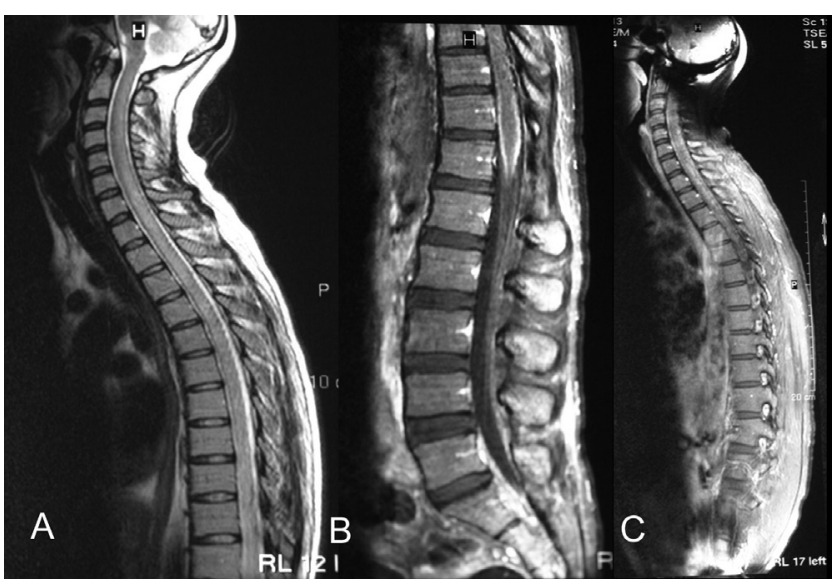

Figure 2 - Non-contrast T2-weighted image showing a diffuse high-signal intensity inside the cervical and thoracic spinal cord (a). Contrast sagittal T1-weighted image showing diffuse meningeal enhancement over the conus medullaris (b). The parenchyma was enhanced heterogeneously on the contrast T1-weighted image (c) 
was added to the treatment for suspected meningitis due to Listeria monocytogenes. After three days of ampicillin treatment, her fever resolved. Ceftriaxone and acyclovir treatment was continued for fourteen days, and ampicillin treatment for twenty-one days.

In order to ameliorate the voiding difficulty, a permanent internal catheter was implanted for six weeks. Ten days later, her fever had diminished. On follow-up five weeks after the initial examination, gait ataxia and cranial and spinal MRI findings had resolved (Figures 3 and 4); at seven weeks, the urodynamic study was normal.

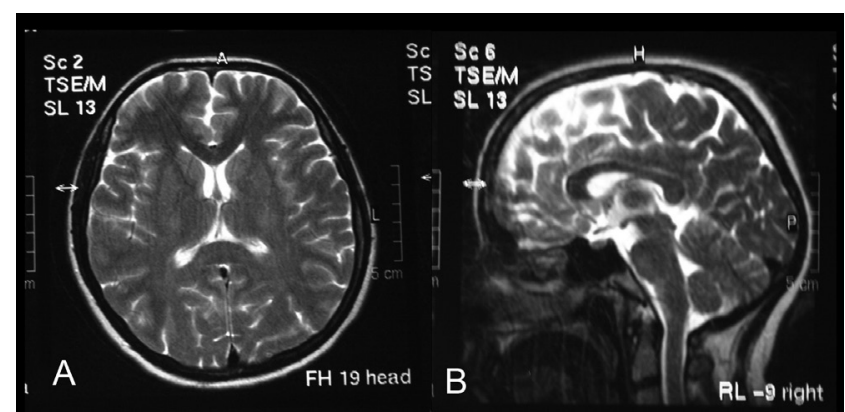

Figure 3 - Transverse (a) and sagittal (b) T2-weighted image showing norma cranial MR findings

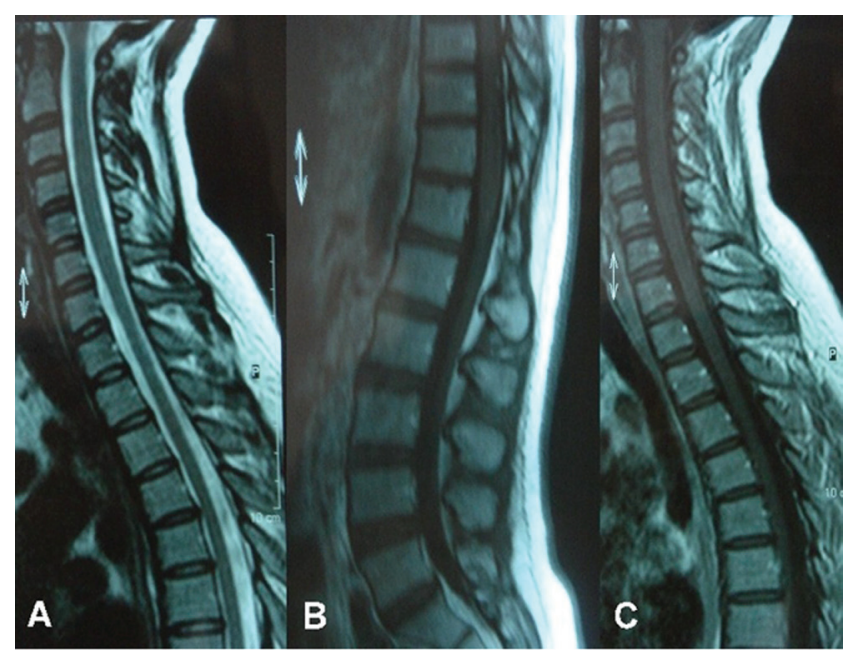

Figure 4 - Non-contrast T2-weighted image of the cervical and thoracic spinal cord (a), contrast sagittal T1-weighted image of the conus medullaris (b), and contrast T1-weighted image of the cervical and thoracic spinal cord (c) reveal normal findings

\section{DISCUSSION}

In clinical practice, it is rare to find only a focal nonhemorrhagic lesion within the central portion of the SCC. ${ }^{23}$ In our patient, it is probable that the posterior CC (splenial) lesion, which is an important cause of dysarthria and gait ataxia ${ }^{4,6,13}$ and which had resolved in five weeks, was due to aseptic meningomyelitis. This condition might have been associated with an overlooked mild metabolic encephalopathy. Although cranial MR findings in our patient suggested that the lesion was ischemic in nature (because of the decreased ADC values), we did not consider ischemia as the causative factor. ${ }^{5,26}$ Furthermore, lesions marked by abnormal signal intensity arising from infarctions are usually irreversible. ${ }^{26}$ However, as observed in our patient, the splenial lesion and gait ataxia can resolve completely.

In 2004, Tada et al. reported clinically mild encephalitis/ encephalopathy in fifteen patients with reversible splenial lesions on MRI. In ten of those fifteen patients (67\%), the pathogen was not clarified, as in our patient. ${ }^{5} \mathrm{~A}$ tendency towards the splenium seems to be apparent in various forms of encephalitis/encephalopathy. It has been suggested that this could be due to: 1) high density of drug and toxin receptors of splenium, which may make it sensitive to vasogenic edema, ${ }^{23}$ and 2) participation of elevated inflammatory cytokines, such as interleukin-6, which may be responsible for the intramyelinic edema or inflammatory infiltrate. ${ }^{2,3}$ Although our patient did not have obvious encephalopathy, second mechanism could also have been responsible for her condition.

The patterns of reversible splenial damage are not specific for a certain disease, but they may be regarded as characteristic of groups of lesions. Differential diagnosis depends on the clinical course and laboratory findings observed for the patients. ${ }^{2}$ Therefore, the most common etiologic factors in reversible lesions of the splenium were excluded from the diagnosis of our patient. We considered that her reversible splenial lesion was mediated by aseptic meningomyelitis.

Splenial lesions could be interpreted as a consequence of a multifactorial pathological process. ${ }^{1}$ For example, if MR examination is not performed for patients with systemic infections associated with encephalopathy/encephalitis, minor asymptomatic splenial lesions could be overlooked. ${ }^{2}$ This holds true for our patient, as we would not have detected the splenial lesion if we had not performed cranial MRI in order to exclude cerebellitis.

Focal lesions in the SCC are thought to be a non-specific endpoint of different disease processes leading to vasogenic or cytotoxic edema. Because posterior CC damage is known to be an important cause of dysarthria and gait ataxia, ${ }^{4,6,13,23}$ patients with meningomyelitis should also be carefully investigated through the use of cranial MRI, including DWI/ ADC, followed by repeated MRIs in order to determine whether the splenial lesion (causing gait ataxia) is transient. ${ }^{23}$ As observed in our patient, the gait ataxia resolved in conjunction with the disappearance of the splenial lesion.

Our patient not only demonstrated a reversible lesion in the SCC, but also reversible acute urinary retention, which is a symptom of urological emergency. ${ }^{34}$ The neurogenic 
bladder observed in our patient was similar to that observed in HSV type 2-induced lumbosacral meningoradiculitis, known as Elsberg syndrome or MRS. ${ }^{39}$ To the best of our knowledge, splenial lesions have not been detected or mentioned in patients with MRS (Table 2). ${ }^{34,36,38-49}$

An underactive detrusor muscle is regarded to be the major cause of voiding dysfunction in neurological diseases, and it originates from various lesion sites in the neural axis. ${ }^{34,50}$ In our patient, an upper motor neuron lesion that affected the spinal cord could have caused an underactive detrusor. Although upper motor neuron involvement was suggested in MRS (combination of acute urinary retention and aseptic meningitis), to date only three cases (four cases including the present case) displayed symptoms suggestive of myelitis. ${ }^{34}$ We thus suggest that it would be better to describe the condition as meningomyelitis-retentionsyndrome (MMRS) instead of MRS. In our patient, myelitis was confirmed by MR findings and fecal incontinence.

MRS has been suggested to be a mild variant of acute disseminated encephalomyelitis (ADEM), which is regarded to have a parainfectious or an autoimmune origin. ${ }^{34}$ Although MRS (or the more correct MMRS) has been reported to follow a benign and self-remitting course (duration of two to ten weeks), urgent management of the acute urinary retention is necessary. ${ }^{34,36}$ Immediate treatment by internal catheterization of our patient resulted in complete recovery in seven weeks.

The incidence of encephalitis/encephalopathy or meningomyelitis with reversible splenial lesion might be higher than previously thought. However, whenever gait ataxia occurs during the course of meningitis or encephalitis/ encephalopathy, it should be kept in mind that, in addition to the myelitis, the ataxia could be due to a reversible splenial lesion, as splenial lesions can cause severe gait ataxia. ${ }^{23}$

The presence of a neurogenic bladder should also be kept in mind when dealing with a patient with meningomyelitis. Although a rare condition, it is a very serious manifestation of aseptic meningomyelitis and should be promptly treated in order to avoid over-distension bladder injury. ${ }^{36}$

In conclusion, mild gait ataxia and acute urinary retention can occur during the course of aseptic meningomyelitis, secondary to splenial lesion and myelitis, respectively. Acute urinary retention should be treated immediately to avoid irreversible damage.

Table 2 - Cranial MRI findings in patients with neurogenic bladder due to meningitis-retention syndrome

\begin{tabular}{|c|c|c|c|c|}
\hline Reference & \# of pts & Illness & Pathogen & Splenial lesion in MRI \\
\hline Kawamura, $2007^{39}$ & 1 & Aseptic meningitis & Probably HSV-6 & $\mathrm{nm}$ \\
\hline Bollen, $2007^{40}$ & 1 & Meningoradiculitis & HSV-2 & $\mathrm{nm}$ \\
\hline Furugen, $2006^{41}$ & 1 & Eosinophilic meningoencephalitis & A. cantonensis & $\mathrm{nm}$ \\
\hline Sakakibara, $2005^{34}$ & 3 & Aseptic Menengitis & - & none \\
\hline Yoritaka, $2005^{42}$ & 4 & Radiculoneuropathy & HSV-2 and other HSV-types & $\mathrm{nm}$ \\
\hline Zenda, $2002^{36}$ & 1 & Aseptic meningitis & - & none \\
\hline Urakawa, $2001^{43}$ & 1 & Aseptic meningitis & - & none \\
\hline Kanazawa, $2000^{44}$ & 1 & Aseptic meningitis & - & $\mathrm{nm}$ \\
\hline \multirow[t]{2}{*}{ Shimizu, $1999^{45, \text { reviewed in } 34}$} & 2 & Aseptic meningitis & - & $1-\mathrm{nm}$ \\
\hline & & & & 1-none \\
\hline Jensenius, $1997^{46}$ & 1 & Aseptic meningitis & HSV- 2 & $\mathrm{~nm}$ \\
\hline Fukagai, $1996^{\text {reviewed in } 34}$ & 1 & Aseptic meningitis & - & $\mathrm{nm}$ \\
\hline Vonk, $1993^{47}$ & 2 & Sacral myeloradiculitis & HSV-2 & $\mathrm{nm}$ \\
\hline Lepori, $1992^{48}$ & 1 & Aseptic meningitis & HSV-2 & $\mathrm{nm}$ \\
\hline Steinberg, $1991^{38}$ & 1 & Aseptic meningitis & HSV & $\mathrm{nm}$ \\
\hline Ohe, $1990^{\text {reviewed in } 34}$ & 1 & Aseptic meningitis & - & none \\
\hline Hemrika, $1986^{49}$ & 3 & Sacral myeloradiculitis & HSV-2 & $\mathrm{nm}$ \\
\hline Kano, $1985^{\text {reviewed in } 34}$ & 1 & Aseptic meningitis & - & $\mathrm{nm}$ \\
\hline Present case & 1 & Aseptic meningomyelitis & - & + \\
\hline
\end{tabular}

\#: number, pts: patients, A.: Angiostrongylus, HSV: Herpes simplex virus, nm: not mentioned MRI: magnetic resonance imaging. 


\section{REFERENCES}

1. Polster T, Hoppe M, Ebner A. Transient lesion in the splenium of the corpus callosum: three further cases in epileptic patients and a pathophysiological hypothesis. J Neurol Neurosurg Psychiatry. 2001;70:459-63.

2. Yaguchi M, Yaguchi H, Itoh T, Okamoto K. Encephalopathy with isolated reversible splenial lesion of the corpus callosum. Int Med. 2005;44:1291-4.

3. Takanashi J, Barkovich AJ, Yamaguchi K, Kohno Y. Influenza-associated encephalitis/encephalopathy with a reversible lesion in the splenium of the corpus callosum: a case report and literature review. Am J Neuroradiol. 2004;25:798-802.

4. Morgan JC, Cavaliere R, Juel VC. Reversible corpus callosum lesion in legionnaires' disease. J Neurol Neurosurg Psychiatry. 2004;75:651-4.

5. Tada H, Takanashi J, Barkovich AJ, Oba H, Maeda M, Tsukahara H, et al. Clinically mild encephalitis/encephalopathy with a reversible splenial lesion. Neurology. 2004;63:1854-8.

6. Hagemann G, Mentzel HJ, Weisser H, Kunze A, Terborg C. Multiple reversible MR signal changes caused by Epstein-Barr virus encephalitis. Am J Neuroradiol. 2006;27:1447-9.

7. Bulakbasi N, Kocaoglu M, Tayfun C, Ucoz T. Transient splenial lesion of the corpus callosum in clinically mild influenza-associated encephalitis/ encephalopathy. Am J Neuroradiol. 2006;27:1983-6.

8. Takanashi J, Barkovich AJ, Shiihara T, Tada H, Kawatani M, Tsukahara $\mathrm{H}$, et al. Widening spectrum of a reversible splenial lesion with transiently reduced diffusion. Am J Radiol. 2006;27:836-8.

9. Yeh IB, Tan LC, Sitoh YY. Reversible splenial lesion in clinically mild encephalitis. Singapore Med J. 2005;46:726-30.

10. Kobata R, Tsukahara H, Nakai A, Tanizawa A, Ishimoro Y, Kawamura $\mathrm{Y}$, et al. Transient MR signal changes in the splenium of the corpus callosum in rotavirus encephalopathy: value of diffusion-weighted imaging. J Comput Assist Tomogr. 2002;26:825-8.

11. Kato Z, Kozawa R, Hashimoto K, Kondo N. Transient lesion in the splenium of the corpus callosum in acute cerebellitis. J Child Neurol. 2003;18:291-2.

12. Maeda M, Tsukahara H, Terada H, Nakaji S, Nakamura H, Oba H, et al Reversible splenial lesion with restricted diffusion in a wide spectrum of diseases and conditions. J Neuroradiol. 2006;33:229-36.

13. Oaklander AL, Buchbinder BR. Pregabalin-withdrawal encephalopathy and splenial edema: a link to high-altitude illness. Ann Neurol. 2005;58:309-12.

14. da Rocha AJ, Reis F, Gama HP, da Silva CJ, Braga FT, Junior AC, et al. Focal transient lesion in the splenium of the corpus callosum in three non-epileptic patients. Neuroradiology. 2006;48:731-5.

15. Winslow H, Mickey B, Frohman EM. Sympathomimetic-induced kaleidoscopic visual illusion associated with a reversible splenium lesion. Arch Neurol. 2006;63:135-7.

16. Gurtler S, Ebner A, Tuxhorn I, Ollech I, Pohlmann-Eden B, Woermann FG. Transient lesion in the splenium of the corpus callosum and antiepileptic drug withdrawal. Neurology. 2005;65:1032-6.
17. Prilipko O, Delavelle J, Lazeyras F, Seeck M. Reversible cytotoxic edema in the splenium of the corpus callosum related to antiepileptic treatment: report of two cases and literature review. Epilepsia. 2005;46:1633-6.

18. Hakyemez B, Erdogan C, Yildirim N, Gokalp G, Parlak M. Transient splenial lesion of corpus callosum associated with antiepileptic drug: conventional and diffusion-weighted magnetic resonance images. Acta Radiol. 2005;46:734-6.

19. Mirsattari SM, Lee DH, Jones MW, Blume WT. Transient lesion in the splenium of the corpus callosum in an epileptic patient. Neurology. 2003;60:1838-41

20. Cohen-Gadol AA, Britton JW, Jack CR Jr, Friedman JA, Marsh WR. Transient postictal magnetic resonance imaging abnormality of the corpus callosum in a patient with epilepsy. Case report and review of the literature. J Neurosurg. 2002;97:714-7.

21. Carrara G, Ferlazzo E, Tampieri D, Andermann F, Melanson D. Transient edematous lesions of the splenium in epileptic patients. Can J Neurol Sci. $2005 ; 32: 352-5$

22. Hackett PH, Yarnell PR, Hill R, Reynard K, Heit J, McCormick J. Highaltitude cerebral edema evaluated with magnetic resonance imaging. JAMA. 1998;280:1920-5.

23. Appenzeller S, Faria A, Marini R, Costallat LTL, Cendes F. Foca transient lesions of the corpus callosum in systemic lupus erythematosus. Clin Rheumatol. 2006;25:568-71.

24. Fogel B, Cardenas D, Ovbiagele B. Magnetic resonance imaging abnormalities in the corpus callosum of a patient with neuropsychiatric lupus. Neurologist. 2006;12:271-3.

25. Kang K, Song YM, Jo KD, Roh JK. Diffuse lesion in the splenium of the corpus callosum in patients with methyl bromide poisoning. J Neurol Neurosurg Psychiatry. 2006;77:703-4

26. Kosugi T, Isoda H, Imai M, Sakahara H. Reversible focal splenial lesion of the corpus callosum on MR images in a patient with malnutrition. Magn Reson Med Sci. 2004;3:211-4.

27. Nishimura K, Takei N, Suzuki K, Kawai M, Sekine Y, Isoda H, et al. A transient lesion in splenium of the corpus callosum in a patient with childhood-onset anorexia nervosa. Int J Eat Disord. 2006;39:527-9.

28. Pandian JD, Henderson RD. "Boomerang sign" in the splenium of the corpus callosum. Med J Aust. 2005;183:628.

29. Kim JH, Choi JY, Koh SB, Lee Y. Reversible splenial abnormality in hypoglycemic encephalopathy. Neuroradiology. 2007;49:217-22.

30. Ogura H, Takaoka M, Kishi M, Kimoto M, Shimazu T, Yoshioka T, et al. Reversible MR findings of hemolytic uremic syndrome with mild encephalopathy. Am J Neuroradiol. 1998;19:1144-5.

31. Okada K, Fujiwara H, Tsuji S. X-linked Charcot-Marie-Tooth disease with transient splenium lesion on MRI. Intern Med. 2006;45:33-4.

32. Tani M, Natori S, Noda K, Fujishima K, Hattori N, Mizuno Y, et al. Isolated reversible splenial lesion in adult meningitis: a case report and review of the literature. Intern Med. 2007;46:1593-6. 
33. Maeda M, Shiroyama T, Tsukahara H, Shimono T, Aoki S, Takeda $\mathrm{K}$. Transient splenial lesion of the corpus callosum associated with antiepileptic drugs: evaluation by diffusion-weighted MR imaging. Eur Radiol. 2003;13:1902-6.

34. Sakakibara R, Uchiyama T, Liu Z, Yamamoto T, Ito T, Uzawa A, et al. Meningitis-retention syndrome. An unrecognized clinical condition. J Neurol. 2005;252:1495-9.

35. Sakakibara R, Yamanishi T, Uchiyama T, Hattori T. Acute urinary retention due to benign inflammatory nervous diseases. J Neurol. 2006;253:1103-10.

36. Zenda T, Soma R, Muramoto H, Hayase H, Orito M, Okada T, et al. Acute urinary retention as an unusual manifestation of aseptic meningitis. Intern Med. 2002;41:392-4.

37. Sasaki M, Ohara S, Hayashi R, Iwahashi T, Tsuyuzaki J. Aseptic meningo-radiculo-encephalitis presenting initially with urinary retention: a variant of acute disseminated encephalomyelitis. J Neurol. 2006;253:908-13.

38. Steinberg J, Rukstalis DB, Vickers MA Jr. Acute urinary retention secondary to Herpes simplex meningitis. J Urol. 1991;145:359-60.

39. Kawamura M, Kaku H, Takayama N, Ushimi T, Kishida S. Acute urinary retention secondary to aseptic meningoencephalitis in an infant-case report. Brain Nerve. 2007;59:1287-91.

40. Bollen AE, Venema AW, Veldkamp KE. Meningoradiculitis caused by herpes simplex virus type 2. Ned Tijdschr Geneeskd. 2007;151:2400-4.

41. Furugen M, Yamashiro S, Tamayose M, Naha Y, Miyagi K, Nakasone C, et al. Elsberg syndrome with eosinophilic meningoencephalitis caused by Angiostrongylus cantonensis. Intern Med. 2006;45:1333-6.
42. Yorikata A, Ohta K, Kishida S. Herpetic lumbosacral radiculoneuropathy in patients with human immunodeficiency virus infection. Eur Neurol. 2005;53:179-81.

43. Urakawa M, Ueda Y. A case of urinary retention secondary to aseptic meningitis. No To Shinkei. 2001;53:742-6.

44. Kanazawa R, Mizutani N, Sanno N, Shimura T, Teramoto A. A case of urinary retention secondary to aseptic meningitis. No Shinkei Geka. 2000;28:1029-33

45. Shimuzu Y, Yamamoto S, Inoue K, Nakamura Y, Tokonami F, Aii H, et al. Two cases of urinary retention secondary to aseptic meningitis. Hinyokika Kiyo. 1999;45:435-7.

46. Jensenius M, Myrvang B, Størvold G. Serous meningitis associated with primary genital herpes infection. Tidsskr Nor Laegeforen. 1997;117:2316-8

47. Vonk P. Elsberg syndrome: acute urinary retention following a viral infection Ned Tijdschr Geneeskd. 1993;137:2603-5

48. Lepori P, Marcacci G, Gaglianone S. Elsberg syndrome: radiculomyelopathy and acute urinary retention in patient with genital herpes. Ital J Neurol Sci. 1992;13:373-5

49. Hemrika DJ, Schutte MF, Bleker OP. Elsberg syndrome: a neurologic basis for acute urinary retention in patients with genital herpes. Obstet Gynecol. 1986;68:37S-39S

50. Fowler C. Short commentary on "Acute urinary retention due to benign inflammatory nervous diseases" by Sakakibara et al. in J Neurol. 2006;253:1103-10. J Neurol. 2006;253:1102. 